\title{
Research on modeling of direct-injection gasoline engine turbocharging process based on AMESim software
}

\author{
Yuqiao Liu ${ }^{\text {a }}$, Yongping Zhang ${ }^{\mathrm{b}}$ \\ Changchun Institute of Engineering Technology,Changchun 130117,China \\ alyq909@126.com, byp909@163.com
}

Keywords: V workflow,AMESim software,the offline model of the engine, the real-time model of the engine, the hardware-in-the-loop(HIL)

Abstract. In order to get the engine simulation model used for the development of control strategy, the offline model and real-time model of self-developed gasoline engine by FAW of direct-injection turbocharging were built based on AMESim software. The results of simulation were compared with that of actual engine test. At steady state condition of 3000r/min and full load, the error of air mass flow was $6.82 \%$, the error of intake pressure was $3.6 \%$, the error of BMEP was $0.097 \%$ and the error of fuel injection quantity was $0.3 \%$. At transient state condition, the operating condition was reflected better by the simulation model of the engine and the transient simulation can be meet. The real-time model was simplified from offline simulation model which was successfully downloaded into the dSPACE simulator and the real-time verification on the model was finished. The Developing time of the control strategy was much shorter by simulation and the developing efficiency of electronic control systems was improved.

\section{Introduction}

With the development of electronic control system, the V procedure for ECU developing has been applied widely. It mainly consists of the definition of control strategy, offline simulation, prototype for immediate control, formation of object code, hardware in loop simulation and calibration process [1-3].

Fig.1 depicts the combination of physical model and real-time model based of the AMESim software platform. The engine model setup by AMESim platform can well predict the engine performance, moreover, real-time model, formed by the simplification of the originate model, can be implemented as hardware in the loop.

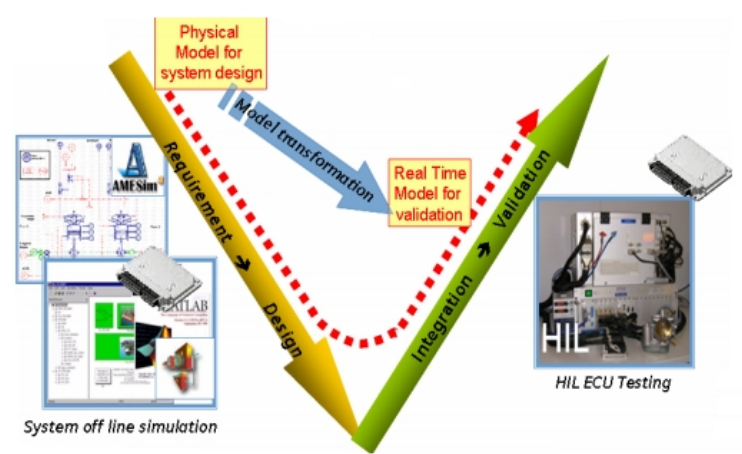

Fig.1 Combination of physical model and real-time model

The present paper mainly focus on the offline engine model setup and real-time model setup based on AMESim platform, as well as the performance tests on the dsPACE simulator by downloading the real-time model to it.

\section{Setup and validation of the offline simulation model}

Model structure. The engine model based on AMESim platform is depicted in Fig.2, which mainly includes compressor, throttle, intercooler, intake and exhaust manifold, injection system, cylinder and 
crankshaft $[4,5]$.

FAW GDI Engine Model

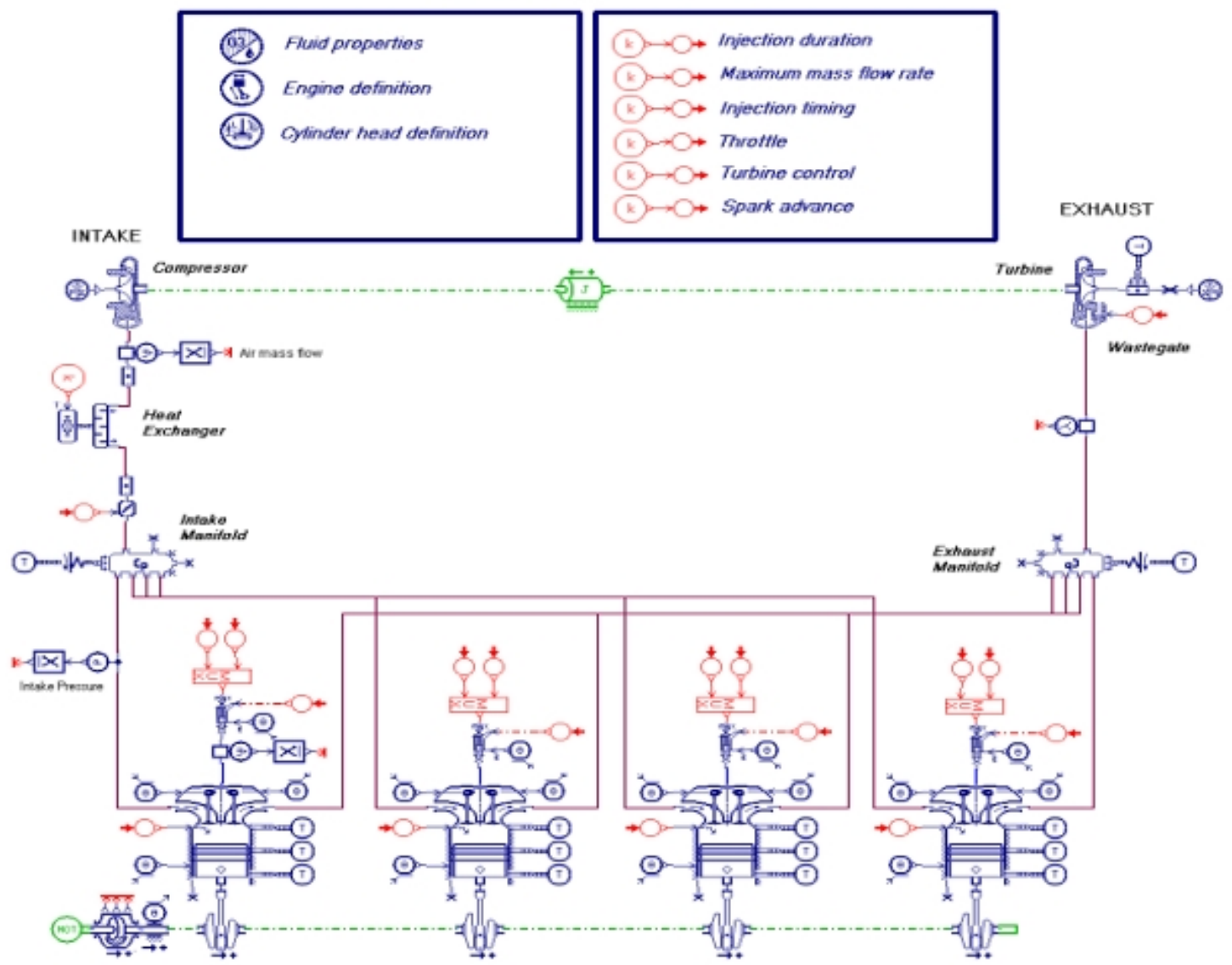

Fig.2 Engine model based on AMESim software

Results of offline simulation. The accuracy of the combustion model, which can influence the performance of engine, is an important part for model set and adjustment. Fig.3 presents the comparison between the computed and test results, where the green line is derived from test and the red line is form the simulation results.

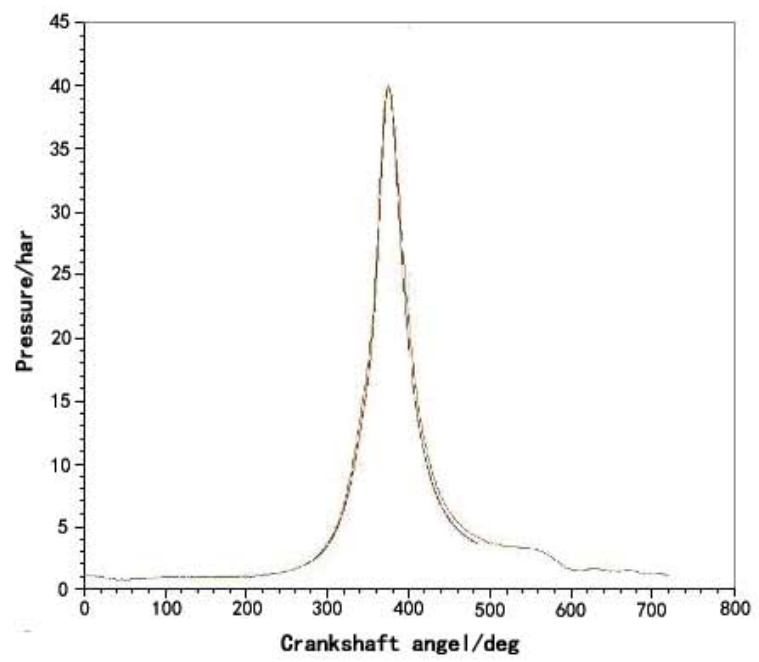

Fig.3 Comparison of cylinder pressure data between simulation and test

Simulation results at steady mode. Fig. 4 demonstrates the simulation result when the engine is at full load with a speed of $3000 \mathrm{r} / \mathrm{min}$. 


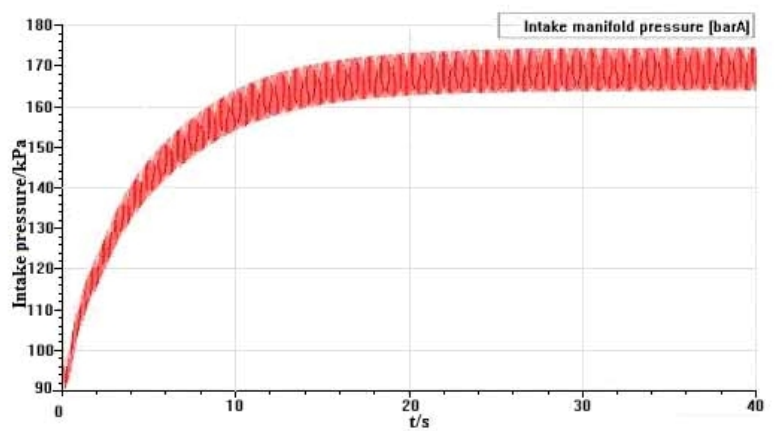

Fig.4(a) simulation result of BMEP

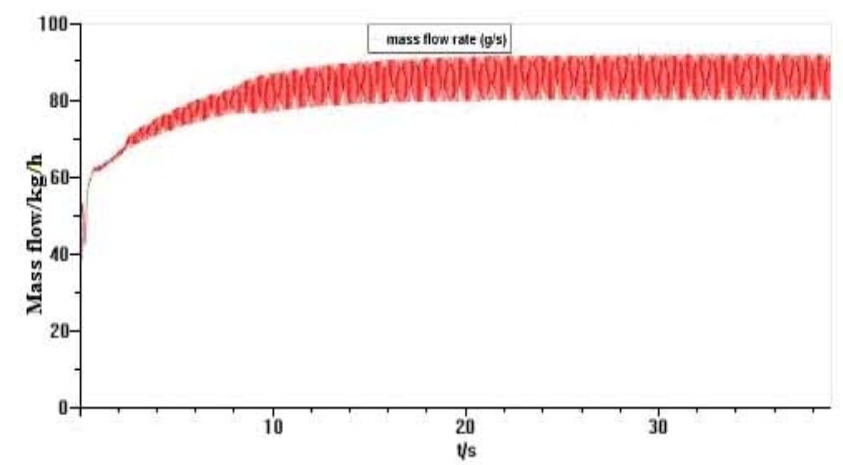

Fig. 4(c) simulation result of air mass flow

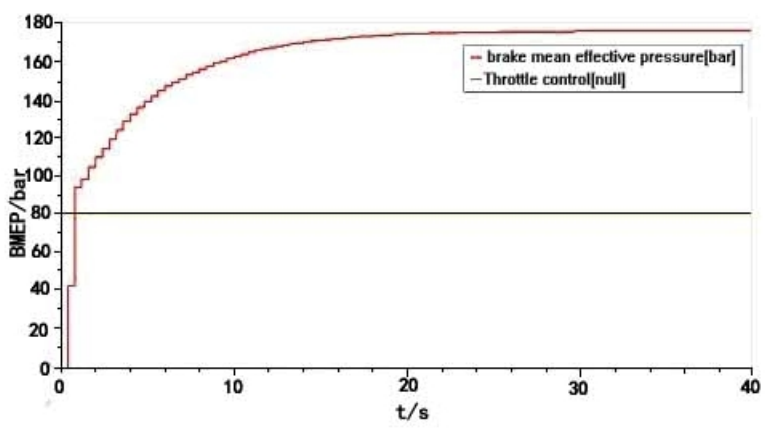

Fig.4(b) simulation result of intake pressure

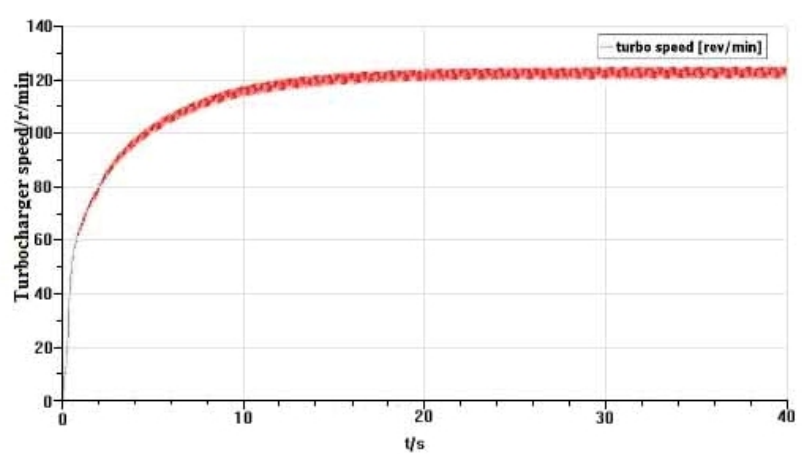

Fig.4(d) simulation result of turbocharger speed

When comparing the simulation results with the test at the right operation condition, the deviation of $\mathrm{BMEP}$ is $0.097 \%$, the deviation of intake pressure is $3.6 \%$ and as to intake mass flow is $6.82 \%$. All the results can well present that the engine model can reflect the engine performance to a great extant.

\section{Setup and valid for real-time simulation model}

An adaptive simplified model can improve the working efficiency for a great extent, the present work mainly focus on the simplification of the model set in previous section with the consideration of real-time capability.

Simplification for the offline model. The real-time model is the simplification of offline model, and the objective of simplifying is to reduce the computation time meanwhile keep the simulation accuracy at an acceptable level. The simplification details are demonstrated as following,

1) Ignoring the operation difference between different cylinders and only take the consideration of the single cylinder.

2) Simplify the intake and exhaust pipes.

3) Optimize the secondary factors.

With the above simplification, the state variables of engine reduce form 64 to 25 , as a result the computing time decreases to $1 / 6$ of the previous value, meanwhile, the simulation results are of little diffrerence.

Validation of model real-time capacity. The simulator implemented in the present work is from dSPACE Corporation, and it can be seen in Fig.5. 


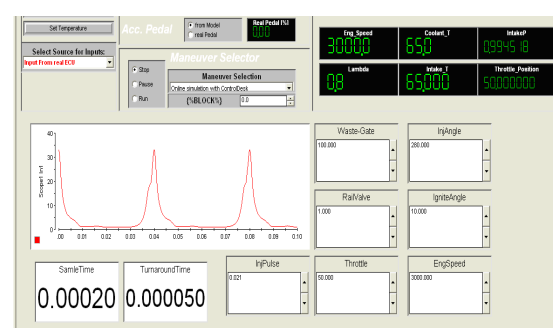

Fig.5 Control interface of ControlDesk

When the model download process is finished, the ControlDesk software from dSPACE can be applied for the purpose of inner parameters adjustment, model parameter monitoring, model input adjustment as well as model output observation, so that an open loop control process is realized.

It can be inferred from Fig. 5 that the maximum step length of the model operated in the simulator is $0.05 \mathrm{~ms}$, which is much smaller than that of the engine model valued $0.2 \mathrm{~ms}$, so it can be concluded that the simplified model can satisfy the engine model operation demand.

\section{Conclusions}

The authors setup the offline for a direct injection gasoline engine with AMESim software, and the simulate the steady mode of the engine with the offline model, the computed results indicate that the model can well satisfy the offline simulation demand. Moreover, the offline model is simplified to a real-time model whose real-time capacity is validated in the dSPACE simulator.

\section{References}

[1] Thierry Bourdon, Landry Saussol ,Bertrand Varoquié,Integration of Physical AMESim® Engine Model in Hardware in the Loop Environment, Dedicated to Engine Control Unit Testing SAE Paper: 2007-01-1300.

[2] A. Chasse, P. Moulin, P. Gautier and A. Albrecht, L. Fontvieille, A. Guinois and L. Doléac, Double Stage Turbocharger Control Strategies Development, SAE Paper: 2008-01-0988.

[3] J. Bohbot, F. A. Lafossas, A. Albrecht, M. Miche, M. Chraibi and P. Menegazzi, A New Coupling Approach Using a 1D System Simulation Software and a 3D Combustion Code Applied to Transient Engine Operation, SAE Paper: 2004-01-3002.

[4] L-M. Malbec, F. Le Berr, S. Richard, G. Font and A. Albrecht,Modeling Turbocharged Spark-Ignition Engines:Towards Predictive Real Time Simulators,SAE Paper: 2009-01-0675.

[5] F. Le Berr, M. Miche, G. Le Solliec and F-A. Lafossas, Modelling of a Turbocharged SI Engine with Variable Camshaft Timing for Engine Control Purposes, SAE Paper: 2006-01-3264. 